\title{
Egorova M.A.
}

\section{A Person in a Multicultural Society: the Problem of Self-identification}

\begin{abstract}
Review. The subject of this research is the review of the process of self-identification that happens on the background of the forming of a multicultural society with all its diversity, and at the same time with specific problems that are inherent for such type of a social construct. An analysis is conducted on the changes of human identity in the multicultural societies, and the attitude of an individual towards the surrounding multicultural world. The article examines the multiculturalism as a blueprint of a social structure in various countries of the world, especially in the countries of Western Europe and the European Union, where the character of multiculturalism is most evident. The author attempts to trace the cooperation of various groups in the framework of multicultural societies within other regions of the world such as Asia (an accent is made on China and Taiwan) and Europe. A conclusion is made on the need to search for a complex approach on the integration of not only groups, but work with separate individuals as well (on the level of schools, institutes, centers for studying the language and culture of the accepting community, etc.).

Keywords: civilization, dialog, integration, conflict, globalization, identity, religion, culture, Nation, society.
\end{abstract}

\section{Multiculturalism in the West}

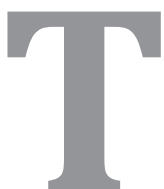

oday, multiculturalism is practically equivalent to the concepts of "Western nations" and "European Union" as geopolitical spaces, which are united by the similarities in values and criteria of the approach towards an individual and the community.

Originating in the West, this term became an alternative to the US and Canada policy of a "smelting pot", which is meant to integrate the immigrants from various parts of the world. Arriving in US or Canada they left not only their entire life behind in order to find a new home, but also their native citizenship and their national or ethnic heritage, becoming Americans or Canadians respectively.

For the countries of the Old World the approach of the "smelting pot" was not always possible. This was first of all related to the fact that the refugees and immigrants who have rushed into Europe after fall of the colonial system were not coming to a community that consisted only of migrants, as was the case with the United States and 
Canada, but into a rather monolith community with a long history, multi-century culture, and not as flexible of a mentality as that of the New World.

For the European countries the influx of immigrants became a real challenge that needed an answer that would fit into the framework of the "democratic approach". Out of the countries of Western Europe only the France throughout its entire history as a nation acquired the most experience and formed strong traditions in the area of unification of ethnic composition in its territory. Across the last few decades Paris has been making attempts to find a balance between maintaining the cultural and language rights of the regions and a strict political centralization. It should be noted that from the beginning France was developing as a country with a strong center with a developed regionalism (especially with regards to language), which throughout the history of a unified French nation strived to suppress regions, including those of the national minority (Corsica, Brittany, The Northern Basque Country - a Western part of the French department of the PyrénéesAtlantiques).

Thus, the 70's and 80's in the West marked the birth of a new concept of cooperation between the representatives of various nationalities and cultures within separate multicultural nations and the European Union as a whole. This concept that received the name of "multiculturalism" represented the idea that the representatives of various nations and ethnic groups would peacefully coexist within the commune, respect and learn the traditions and customs of each of the national segments of the community, and considering themselves citizens of the accepting country would retain their national identity, culture, religion and traditions.

The processes of globalization and cultural integration allowed speaking of a fore- seeable emergence of a unified sphere of a panhuman culture. There are practically no pure ethnic cultures left in the world today. But it is namely the increasing interconnection of the global society that intensifies the interest towards a cultural uniqueness. Therefore, despite the integrational processes the craving for an ethnic personal identification remains rather persistent ${ }^{[1]}$.

The splash of the ethnic uniqueness is a defensive response of the human psyche to difficulty, facelessness, and instability of the modern life. It the today's society an individual is simultaneously a part of multiple groups, the models of behavior of which can even contradict one another. Therefore, striving for stability becomes a significant motive of behavior. Turning to the deep ethnic values fulfills the human need for stable life guidelines. For a human the ethnos begins to play a role of an information filter. The entire flow of information is being structured by the worldview that is based on the ethnic values, which lie within the subconscious layer of the human psyche. Only when the reality absolutely does not fit in the already formed picture of the world, the ethnos begins to form a new one, while attempting to preserve the previous worldview foundations ${ }^{[2]}$.

In political commentator Patrick Joseph Buchanan's opinion, we are currently witnessing "...the death of the nation-state. Men have begun to transfer their allegiance, loyalty and love from the older nations both upward the new transitional regimes that are arising and downward to the sub-nations whence they came, the true nations, united by blood and soil, language, literature, history, faith, tradition and memory" ${ }^{[3]}$.

The changes to the national borders, wars, globalization, financial crises, and other cataclysms and changes such as intensification of the traffic flow, work migration, illegal human trafficking, etc. lead to a mass relocation of people from multiple, mostly 
underdeveloped countries with a low living standards to the more economically developed countries. Among the accepting countries were those with the relaxed conditions for entry of immigrants, such as the United States, Canada, Australia and some European countries.

The people that immigrate into various other countries, for example from the countries involved into a military conflict, escape into bordering nations. Those who emigrate from the countries with lack of opportunities for work or business move to the countries that already have their homeland community (diaspora) and have favorable atmosphere for finding a job or conducting business (for example, a massive outflow of Chinese into the neighboring countries with a higher living standard, with an existing Chinese diaspora (Singapore, Malaysia, Indonesia, etc.)) due to the strive of Chinese people to run their own business, which in their culture is synonymous with wealth and success.

For many countries the issue of cooperation between the immigrants amongst themselves and with the accepting nation was initially played out rather differently. In some places the relations were tolerable from the beginning thanks in part to the conditions (for example in Australia, where the materialistic stability mixed with rigid conditions for entry and the criteria for selection of those entering the country), while in other countries less tolerable (Malaysia had painfully reacted to the growing Chinese population, who participating in ethnic businesses were quickly gaining influence upon the municipal authorities, were monopolizing financial resources, and even attempted to exert influence upon the Malaysian politics).

However, some countries should be singled out, especially those where the social-political was built on the principles of democracy, and where the "smelting pot" and "multiculturalism" were the main conditions upon which to build the relations within the ever-diversifying communities by national and religious principles.

\section{Multiculturalism: diversity without unity}

The idea of multiculturalism carried in itself valuable traces of important truths, which planted into the soil of the countries (European and others) yielded completely different crops than people were expecting.

Multiculturalism that was proposed from "above" by the governments of the European nations was supposed to serve as an alternative to assimilation. It offered a "soft" integration of immigrants from various countries into the accepting monoethnic community with preservation of their traditions, customs and religious confession. Such approach was supposed to allow maintaining their national self-identity while changing citizenships.

The motto of the multiculturalism became the formula "unity in diversity". The ideal was considered to be a prospering country, home to various nations and ethnos that not only peacefully coexist with each other, but are also integrated into the life of the country, which in turn accepts the immigrants while considering them as not just an influx of the workforce, but also a source of various cultures, which as the sources feed the river, feed the culture of this country making it more rich and diverse.

One of the main conditions for multiculturalism became the requirement to not only acknowledge the existence of other cultures, but to respect them as well. Thus it underlines the divide between the notions of "acknowledge" and "respect" with regards to multiculturalism; although one follows the other, one cannot exist without the other. The reality turned out to be far from the ideal: in many of the multicultural countries, especially those in the European 
Union, the certain level of acknowledgement of the incoming cultures was achieved by great effort; next step - the respect - became even harder to achieve. It is doubtful that some aspects of foreign cultures can ever really be accepted, and even more so respected by the "Western" people. For example, wearing the hijab or the sad fact of the disparaged position of women in Muslim families became some of the sore subjects in the Western multicultural communities.

The low birth rate and aging amongst the native population of the accepting country, the economic decline of the 2000's, growth of terrorism, high birth rate among the majority of immigrants, especially within the Arabic, African, Mexican and Chinese communities along with other factors led to the fact that once the accepting countries came to their senses, they were faced with one of the major problems of the recent years: multiculturalism, or how to coexist in one country for those who simply cannot coexist, at least due to the presence of "insurmountable differences". But to "roll back" this situation proves to be very difficult, if not impossible.

The pressing problem of lack of workforce led to the fact that in many countries (especially in Western Europe) a number of fields were completely overtaken by immigrants. For example, in Spain the farms are predominantly staffed by the immigrants from the nations of Northern Africa, Central America and Eastern Europe; in Germany most of the construction workers are from Poland; in Italy the social workers, nannies and caregivers are citizens of Ukraine and Moldova.

Many of the immigrants prefer not to work at all, since initial welfare for the unemployed was so sufficient that it was better to remain unemployed than work for wages far lesser than the government assistance. The idle young people prefer to spend time doing nothing, which leads to turning to illegal activities that result in breaking the law and growth in crime in the housing communities, and later spread across the entire nation. For example, according to research the growth in criminality in Italy was linked to the growth in the 2000's of the immigrants from Maghreb, Sub-Saharan Africa, and Gypsies form Romania ${ }^{[4]}$.

The increase of immigrants within the countries-recipients, especially people without education, laborers, individuals with a low cultural and often moral levels, contributes to the growth of instability and crime, and subsequently a surge in nationalism, and even lately fascism and extremism. Such situation is characteristic for the entire Western Europe, particularly the problem is most prevalent in the countries of the neofascist axis - Germany, Austria and Italy (and extremely prevalent in the latter ${ }^{[5]}$ ). At the same time, the countries of Eastern Europe are also not avoiding a problem, as the migration of the workforce into the West creates the need for more laborers at home ${ }^{[1]}$.

The immigrants blame the accepting community for antagonism, racism, nationalism and xenophobia. But now it becomes more and more evident that it is the immigrants who move to the new country are often unwilling to accept it as their new homeland. And this includes not only the great number of illegal immigrants. Only a smaller part of the immigrants has the necessary command of the language of the accepting country at the level that would allow them to study, work, and integrate into the system. Many of them do not want to study at all, since their goal is to join the community and begin working so that they could afford to live at the same level as the citizens of the accepting nation, or often to be able to send money back home to the family members.

The religion component of the problem of multiculturalism also often results in an 
outburst of anti-Islamic movements. For many Europeans the Muslims and their religion carry a threat to the European wellbeing, since Islamic religion contributes to a rapid growth in Muslim population, part of which, especially youth, is objectively viewed as aggressive and dangerous. Comparing their standard of living and their position within the community to the standard of living and the position of native Europeans, the Muslims (often along with the settlers from Maghreb and Sub-Saharan Africa) begin to express their discontent on the streets of European cities (street riots of 2005 in Paris, Belgium, Germany and Denmark), openly challenging the communities that accepted them. Lack of life perspectives, disappointment, low level of education and culture force them to seek refuge in religion, which is often exploited by the radical Islamic preachers, who call the youth to join the "holy war" against the infidels ${ }^{[1]}$.

All of these creates a divide and antagonism between both sides, and a viscous circle of disconnect and aggression. In addition to that, the people who usually come to the European countries are those who work in entry-level positions, laborers, or people with no profession of any kind. In the conditions of economic crisis the number of jobs shrinks, which mostly affects the immigrants, especially illegal. Losing the opportunity to find a job, even those who did want to work resort to joining the underground, forming into gangs (primarily among youth) and participate in thefts, robberies, violence and murder ${ }^{[1]}$.

There is a notion that the European countries are not doing enough to create an atmosphere for the integration of immigrants into the community. However, in our opinion, it seems more realistic that it is the immigrants themselves, more specifically those from the Arabic and African nations that are predominantly do not want to incorporate themselves into the system, accept the local culture, traditions and customs, study the language and work, preferring to conduct criminal business or receive government assistance.

Thus the process of self-identification of the immigrants within the multicultural community that accepts them takes place beyond the framework of this community. Patrick Joseph Buchanan claims that the "Arabs and Turks in Europe identify more and more with the Islamic faith they have in common and the countries whence they came, not the one in which they live and work" [3].

Until now, there were very minimal requirements within most countries for the level of language necessary for the immigrants, let alone knowledge of the history and culture of the accepting country. With the majority of immigrants consisting of people with low level of education or complete lack thereof, their refuge becomes the religion in its most radical forms.

The most difficult for the accepting community to accept are the newcomers that practice Islam. The reaction to the influx of Muslim migrants and growth in their political and economic demands became the fact that the radically-spirited representatives of the accepting countries, along with the ethnic minorities that are native to these countries began evermore often turning to neo-Christianity with mixing into it aspects of neo-Paganism (Celtic, Druid and other cults). They mythologize or popularize the pages of their history, strengthening in the understanding of their importance, and for the ethnic minorities this became grounds for claiming more independence (for example, the Lega Nord appeals to the Celtic heritage of Padania and underlines that the people of Padania are ethnically different from the people of the central and southern Italy) ${ }^{[5]}$.

Thus, we can say that in the process of finding their ethnic identity many people 
who became disillusioned by the multicultural politics of their countries prefer to associate themselves not with their nation that has been watered down by the members of other cultures, but with their historical ancestors.

In an attempt to find "themselves", many are turning to religion seeing it as one of the paths to self-identification. On the background of multiculturalization of Europe, as well as globalization of Europe and the European integration the question of religious component in the European community, where the religion over the last decades have lost many of its positions, once again begins to gain its relevance. One of the major contributors to this fact was the parallel process of the Islamization of the world, including Europe.

The former head of the Roman Catholic Church the conservator Benedict XVI was unable to offer an adequate answer to the challenges of time; therefore, his role was reduced to the fact that he became a "transitional" Pope. Being a skilled administrator he was able to organize the advancement of the Catholic Church into a new era after John Paul II; he could not however make the breakthrough for the Church to become the foundation for the European Christian identity under the conditions of de-Christianization of Europe. Because of this, the great hope is laid upon the shoulders of his successor the Roman Pope Francis, who is considered to be more liberal and capable to attract new followers into the religion and raise the prestige of the Catholic Church after a number of scandals (financial, ethical, and others) that have emerged during the time of his predecessor.

An upsurge in terrorism acts throughout the world and the fact that behind the majority of them stand various Muslim organizations resulted in the worldwide demarcation of impassable divides, some that separate the West and the East, others separate the
Christian and non-Christian civilizations, and rich and poor regions of the world. Each of these divides reflects on the multicultural communities, becoming a scar that can no longer be masked. In the Western Europe and many countries of other regions of the world people have started to speak louder and more boldly about the failure of the idea of multiculturalism. The multicultural dialogue has come to a dead end.

In the multicultural society the representatives of various cultures within their own group are interlinked by a common language, which serves not only as a universal code of communication within the cultural community, but also becomes a virtual border that separates this culture and linguistic commonality from the other.

The dialogue serves as an important means of building tolerant relations that are based on mutual respect and understanding. It would seem that today such relations in the multicultural societies become unrealistic, with the exception of perhaps the American and Canadian communities, who mainly differ by the principle of their forming. If the American and Canadian communities initially formed as multicultural, the European countries from their very conception consisted of mono-ethnic communities or the ethnic minorities that have historically lived in the territories of these countries. Multiculturalization of such countries was "unnatural" and was often taking place against the will of the radicallyminded segment of the community. If at the beginning of the multicultural project this radical segment was rather insignificant, then in the recent years we can see a tremendous growth in the negatively-minded citizens, which in turn leads to the increase of popularity of the nationalistic and antimigrant ultra-rightwing parties.

Some of the European leaders - the current Chancellor of Germany Angela Merkel, former President of France Nicolas 
Sarkozy and the current Prime Minister of UK David Cameron have openly proclaimed the failure of the idea of multiculturalism (which gained a disdainful term of "multiculti") and the necessity to correct the policy in this regard ${ }^{[6]}$. A question was raised on the need for a state primary (leading) culture that would become dominant in the community.

\section{Multiculturalism in Asia}

For the Asian cultural space (especially the Southeast Asia) polyethnicity is a historically formed fact, which in turn contributed to a rather high level of Asian tolerance with regards to various ethnic minorities, religions and cultures, and all these in the conditions of absence of democratic ideas that are inherent to most of the European countries. Of course, a great factor in such tolerance is the Buddhist religion, as well as a low level of migration into most of these countries, which were not a coveted place for immigration. Thus their polyethnicity was historically formed, rather than a result of the immigration processes.

However, in the $19^{\text {th }}$ and $20^{\text {th }}$ centuries the mass migration of people has also begun to happen in Asia. The main stream of immigrants was coming from China into the neighboring countries of the region: Singapore, Malaysia, Indonesia, Philippines, and others, which has substantially contributed to the anti-Chinese movements within the region. Malaysia had several mass antiChinese acts of protest, and the government was forced to take a number of measures aimed at weakening the influence of the Chinese diaspora in the country ${ }^{[7]}$.

With regards to the China itself, the level of tolerance within the country is fairly high. Almost 95\% of the population regard themselves as "Han Chinese"; although China covers such large territory, it is obvious that this territory was home for many ethnic groups in the past. It is likely that the long history of this nation, which by some estimates has formed as a unified country approximately 2,000 years ago has contributed to the fact that the ethnoses at a fairly early stage were united into a mono-nation within an empire that was always oriented towards a political centralization and ethnic unification. This in turn formed a strong sense of national identity among the Chinese, meaning the Han ethnic group, which has established the nation and populate the eastern part of China. Although the western "non-Han" territories make up almost half of the overall landmass of the country, it is home to just $5 \%$ of ethnically different "non-Han" citizens of China.

Thus we can say that almost $95 \%$ of the population many centuries ago have already become a unified nation, forming a strong commonality of ethnic identity, and the historically newly annexed western territories are unable to dilute and shake the collective homogeneous identity of the Han. All who were not Han were considered as barbarians, and to become a Han was equivalent to becoming a part of a civilized people and a unit in a great empire.

From the beginning of the Chinese economic reform in 1978 a great number of foreigners have started to come to China. The Chinese in turn started to mass migrate to other countries to conduct business or study. This led to the broadening of their contact with foreigners, not only with $\mathrm{Eu}-$ ropeans, but with Africans, Latinos, Arabs, and citizens of other various countries of Oceania and Southeastern Asia. It is worth mentioning that as Chinese see themselves as an ancient unified nation of Han contributes to the fact that they tend to view the people of other countries in a "continental" manner, rather than "country" manner. For example, Chinese tend to view the representative of Africa as Africans, rather than citizens of one or another African country. The Europeans in their eyes are the citizens of the European Union. 
The Republic of China (Taiwan) is de facto independent from China, but in recent years they have experienced a strong influx of Chinese from the mainland, which challenges the independence of Taiwan and tests the resolve of the ethnic self-consciousness of the Taiwan people. The Chinese who arrive on the island overall subdivide into two main groups: wealthy businessmen and investors who buy-up the controlling share of stocks of the major Taiwanese companies (including mass media), and cheap, often illegal workforce from the mainland (including those involved in the criminal enterprises: prostitution, human trafficking, drug dealing, etc.).

Although the Taiwanese, same as Chinese, consider themselves a part of the "Huaxia", observing the immigrants from the mainland they begin to view themselves as the "better version" of the representatives of the "Huaxia"; this reaffirms the notion of independence and the autonomy of their state within their national self-consciousness.

Throughout the entire later part of the $20^{\text {th }}$ century Taiwan has experienced an active economic boom, becoming one of the four "Asian Tigers". This attracted to the island a great number of immigrants from the countries of Southeastern Asia such as the Philippines, Indonesia, Vietnam, Malaysia, Thailand, and others. Most of these immigrants are working in the field of hard (dirty) labor doing the jobs that the Taiwanese do not want to do, as well as working in the nursing and caregiving industry. Most companies prefer to bring in the cheap labor from these countries, rather than hiring the highly-qualified Taiwanese who demand the fair wages for their work. Majority of the immigrants do not have work permits, and those who do at the end of the term of their permit do not return home and prefer to remain in Taiwan illegally.

Thus we can say that the problem of multiculturalism in Taiwan does not stand far from the one in Western Europe. The greater tolerance of the Buddhist-Confucian civilization however, contributes to the smoothness of the intercultural and interethnic relations. At the same time, the Asian immigrants in Taiwan are not extremely active in pushing their political or economic demands to improve their position, which differentiates their situation from that in Western Europe. It would seem that this is related to those democratic alignments inherent to the Western Europe, as well as the great attention that the Europeans pay to human rights and rights of refugees and those who are forced to relocate.

In addition to that, in both China and Taiwan (although less in the latter) the majority of the population is "Huaxia", who represent a common cultural and civilizational selfconsciousness and therefore become the obstacle to forming the true multicultural communities regardless of number of immigrants.

\section{Identity and self-identification}

The problem of multiculturalism serves as a background to two interlinked processes: identity and self-identification.

Identity is a set of codes and symbols that allows a person to find their place in the society, regardless of whether it is a community where they were born or a community where they happen to live. People identify each other by this unspoken set of codes, determining each other's place within various social segments, and in doing so structure their initial understanding and perception about each other.

There are several different types of identity: gender, race, ethnic, religious, cultural, and others. In this article we are interested in the types that are especially evident in a multicultural setting, i.e. ethnic, cultural and religious types of identity.

It is worth noting that a person does not have one identity, but several. They manifest themselves to a higher or lesser degree de- 
pending on a situation that a person is in. For example, for Italians it is important to identify themselves as representatives of Italy; however, inside Italy it becomes important for them to identify themselves by place of birth. Thus, for a Sicilian would be very important to realize their Sicilian identity, rather than Italian. In addition to that, continuing to review this example we can note that once within Sicily, the importance would shift to gender identity, professional identity, language, etc. Furthermore, beyond Italy for many Sicilians their identity with regards to the homeland prevails not only over their Italian identity, but also with regards to their new homeland. For example, many performance artists being citizens of other countries (or having a dual citizenship) even go as far as emphasizing their Sicilian identity in their art using the motifs of their homeland in their music. We can notice in the work of such famous Sicilians as Frank Sinatra, Salvatore Adamo, Roberto Alagna and many others.

Personal identification is a necessary element of development of personality that takes place at the fairly early stages of forming a personality and can be corrected in a certain amount of time. Unlike identity, the self-identification is rooted within personality, and its development becomes rather painful if it goes in contrast with how others identify a person. Some people tend to be sensitive about how others see them if it is different from how they see themselves. For example, for a person who considers themselves a representative of a titular nation it is often unpleasant to hear that on their father's or mother's line, or by both parents, they ethnically do not belong to a titular nation. For example, we can remember Mikhail Lermontov who often dwelled on the fact that by a twist of fate he was separated from his historical motherland Scotland and is far from his national roots, to which he has dedicated his poem "The Wish".
The problem of personal identification exists and is important for every human, regardless of their education or cultural level, faith, political beliefs or place in the society. On the contrary, all of these things only "provoke" a person to find approaches towards understanding their inner self, to find their place within the society they live in.

The necessity to find one's self intensified at the same time the communities began to develop a multicultural character and resemble a mosaic of cultures, nations and religions. Thus, the identity started to play even a bigger role than it did in the monoethnic communities.

\section{The role of the language}

The establishing of personal identification can be possible only in cooperation of people, in their communication with each other, and their reaction to the people around them and the environment they are in. Personal identification is a process of constant reflexes of human consciousness to what is happening around them, to the changes to life's circumstances, new people, their social mobility and professional activity. In their childhood, a person can not dwell on who they are, what their nationality is, or what language they speak until they find themselves part of their first society - kindergarten or school. There, in interaction with other children and teachers they begin to realize who they are in relation to others. This is especially present in the poly-ethnic and multicultural regions. For example, in China the language variance goes against the policy of the Communist Party of China, aimed at advancing the national language of Putonghua. Arriving at school, the children realize that the language they speak in their family, their village or city is different from that spoken by other children or their teachers. When it comes to China, the teachers have to use only the language of Putonghua within the walls of the school, 
and the children are forbidden to use their own language even during recess ${ }^{[8]}$.

Such sharp life moments allow people to begin on their path towards self-identification and self-realization. Later in life, during the course of college education that can take place far from home or even in a different country, a person sees themselves as a representative of a certain community that is different from the one they are currently in. Ending up abroad, a person feels as a representative of their nation, a carrier of their national language and culture. It is one of the best methods of advancing on a path of personal identification and the search of one's place within the world structure in the later years.

The self-confidence is based on the realization of what the person is a part of (ethnos, nation, language group, country, etc.). Being a part of something greater, a person not only shares the positive characteristics of that community, but also the negative stereotypes that are associated with it. For example, the Sicilians, often as a joke, at times with certain sadness speak about the fact that being a Sicilian makes it hard for them to avoid a question about mafia, including Cosa Nostra; but at the same time it is a priori believed that the Sicilians are musically talented and artistic, and possess great vocal abilities from birth. Thus, it is evident that the personal identity of a separate member of a group is tightly linked with the identity of all members of this group (ethnic, linguistic, etc.). Without a doubt, its external characteristic to which members of other groups first pay attention has a strong effect on the self-consciousness of every individual in the group.

Within the framework of a community its members are connected between each other by a set of symbols, codes, features, traditions and customs, language and religion, all of which tie them and become their provisory signals in the identification of each other and simultaneously differentiates them from the representatives of other groups.

One of the key linking components of a group is the language of its members. Within the framework of linguistic philosophy Ludwig Wittgenstein wrote about a word as the primary means of coding information, viewing the language as a form of life. "The limits of my language mean the limits of my world" (5.62) ${ }^{[9]}$.

Based on this observation, for this writer the limitations of the world are set by the language in which he writes. Translation into other languages, even if made at the highest level always take away from the language of the source.

Each individual language, regardless whether it is rich or not, melodic or abrupt - deserves the most thorough comprehension. Language is not just an imprint of a nation's ideas, but a unified spiritual energy of particular people, which is miraculously captured in certain sounds and through the interconnection of its sounds understandable to all who speak it, and invokes approximately the same energy within all of them. A person does not fit within the boundaries of their language; they are greater than anything that can be described in words; but a person has to confine their imperceptible spirit into words in order to solidify it with something and use words as the basis to achieve that which goes beyond its boundaries. Different languages are not just the various designations of a same thing, but rather a different way of seeing it; if this thing is not an object of an external world, then each person who speaks about it creates it in their own way. Languages are hieroglyphs into which a person confines the world and their imagination. Through the variation of languages we discover the richness of the world and everything we learn within it. Our life becomes broader as languages give us different ways of think- 
ing and perceiving things. The language always embodies the uniqueness of an entire people... ${ }^{[10]}$.

Self-identification is impossible without comprehension of one's native language and its place within the world. It is natural for a person to cling to their native language. For uneducated people the language comes through the system of verbal legends and myths. For educated - it is the entirety of literature and written sources created in their language. Even in the cases of bilingualism a person tends to choose a language that more precisely represents their picture of the world and matches their matrix of personal identity.

The longevity of a language is equal to the problem of establishment of selfconsciousness of a nation and ethnic selfidentification. For example, for countries and regions such as Catalonia, Basque Country, Scotland, Wales, Ireland and others the establishing of national identity began simultaneously with the beginning of rebirth of the native tongue. The same phenomenon can also be observed in other regions of the world (e.g. Abkhazia). For the youth in the process of their self-identification as part of a nation rather than supranational state (e.g. the Welsh) an important step became the study of their own language and broadening the sphere of its use. For the countries that have recently gained sovereignty (Abkhazia) the rebirth of the language became one of the types of weapons in the fight for the right to statehood.

\section{The problem of self-identification} as self-discovery: personality and society Within a mono-cultural society the processes of self-identification are diluted and can take place much later in person's life than it normally happens in people within multicultural societies. Multiculturalization of majority of the world's countries has brought accelerated and deeper processes of self-identification. A person begins to discover their own "self" and counterpose "our" against "their" at much earlier stages of their development, and this feeling becomes sharper than it was before.

Becoming a part of a multicultural environment people act differently in apprehension of this environment: some become more "withdrawn", attempting to find strength in their own culture and personal identity, while others integrate quite easily and see themselves as a part of the mosaic society.

In many aspects people's behavior is not only affected by the environment they find themselves in, but also by their personality, character and mentality. For example, the type of people with the so-called "easygoing" character, often display such qualities as communicability, flexibility, etc., and at times demonstrate rather low level of patriotism (e.g. love for their motherland that they left behind) or complete lack thereof (if in their own country they felt discomfort, and the new home has compensated it). In addition to the underdeveloped sense of patriotism, such people also demonstrate a low level of nationalism and chauvinism. Thus, they are not as able to feel as a part of their national and cultural space and remain loyal to it.

For such people the new multicultural environment is a type of an Eastern bazaar, where separate persons are not as important as their ability to cooperate and find common ground.

Such people possess many positive personal qualities: broader views, tolerance, openness, communicability - all of these traits allow them to quickly integrate and find common ground with the representatives of various cultures. Moreover, people around them are often attracted to such people, and in a way create the environment for communication and cooperation. This provides a favorable atmosphere for 
such people regardless of where they move. They do not suffer from loneliness or loss of themselves in foreign cultural communities. They do not need to break their principles or cultural guidelines in order to cooperate with the representatives of other cultures. Naturally, we can say that such people do not have a deeply rooted personal identity.

The process of self-identification is tough and often quite lengthy. It can take place across a significant part of a person's life, gaining or lowering the amplitude depending on the circumstances that accompany it. This process can often carry a quite painful character among those people for whom their personal identification is very important.

One of the possible situations is when people are born to parents of two different nationalities. They are often faced with a painful split of their national personal identity, which can be further aggravated by the fact that the person lives in the country where one of the parents represents the dominant nationality of that country, but at the same time the other parent demands respect for the other nationality that they represent. For example, within the Armenian-Russian families living in Russia it is often the father who represents the Armenian nationality, and mother represents the Russian. In such families it is easier for a child to identify themselves as Russian, as living in Russia and identifying themselves as Russian helps to integrate into the society within which the process of self-identification will take place. Often however, it does not suit the Armenian father, who demands that the child remembers their Armenian roots, studies the language, and upholds Armenian traditions. In these cases, the process of selfidentification of the child can involve mixed feelings and their development can be very stressful, not allowing a child to easily understand their place within the society. This situation can worsen when a young person at the very beginning of their maturity arrives in a multicultural environment, where their duality is worsened by the fact that they must integrate into a society that although mosaic, does not have a segment that is appropriate for them. For example, when they immigrate into a country and live in the city that does not have the ethnic community to which they attribute themselves. In such situations people often attempt to identify themselves within religious of professional types of identity. If we continue to review the example of a person of Armenian-Russian nationality, such person can become close with the members of the same faith or identify themselves with a professional community that is close to their type of work. This allows them to escape the feeling of loneliness, detachment or feeling lost in the crowd. In such situation the self-identification serves as an anchor that allows a person to not float in the open sea of a multicultural society, but find their place within it, the harbor in which the person finds the source for their spiritual strength and will be able to observe the world and discover their self.

\section{Conclusion}

Today we can say the world is no longer divided into East and West, Christian and Muslim, developed and developing. The world that we see challenges us in various new ways. All of them can be combined into one - a fusion of too many different micro and macro groups (ethnic, national, religious, and cultural) within the framework of one society. The processes of diversification of societies only gain momentum in the course of unveiling of regional conflicts, epidemics, famine, and unemployment that all produce new refugees. All of these circumstances force the migrants to seek better future in the places that were previously accustomed to live in a fairly unified manner; a place that is now challenged by the foreign cultures and ideas. 
To artificially stop these processes seems impossible, but it is important to learn to integrate the newly arrived into the life of the society without "breaking" its traditions, as artificial "breaking" causes the society to reject the foreigners, provokes extremism, nationalism, and even xenophobia in the places that were always ruled by democracy, respect of personal rights, multiculturalism, and religious and racial tolerance.
The accepting communities are faced with an important challenge: learn to manage the processes of integration not only on a macro level, but also on the level of individual approach towards separate persons, as each human acts as a single unit that carries the culture and traditions of the country of their origin, and often just one person is capable to disrupt the entire community that did not accept them and give them a vicious challenge.

\section{References (transliterated)}

1. Egorova M. A. Globalizatsiya i evrointegratsiya kak vyzovy etnichnosti // Politika i obshchestvo, № 10, 2009. (s. 49-63).

2. Kul'tura sotsial'no-etnicheskikh obshchnostei http://www.culturology-blog.ru/kulturasocialno-etnicheskix-obshhnostej/

3. Buchanan, P. J. The death of the nation state / WorldNetDaily, 23.05.2006 // http:// www.wnd.com/news/article.asp? ARTICLE_ID=50338

4. Papa, Controlli In Centro E A San Pietro: Presi 14 Borseggiatori / La Repubblica // http://roma.repubblica.it/dettaglio-news/papa-controlli-in-centro-e-a-san-pietropresi-14-borseggiatori/19189, 19.03.2013

5. Daniel Greenfield $52 \%$ of Rapes in Rome Committed by Immigrants, $59 \%$ in Milan, 40\% in Italy http://www.frontpagemag.com/2012/dgreenfield/r-of-rapes-in-romecommitted-by-immigrants-y-in-milan-in-italy/, 26.12.2012.

6. Egorova, M. A. Problema samoidentifikatsii Severa Italii / Politika i obshchestvo, № 8(50), 2008, S. 23-37.

7. The Westphalian Post Of Westphalia and Appomattox https://westphalianpost.wordpress.com/tag/multikulti/ 01.05.2013.

8. Hui Yew-Foong Sinophobia smolders in Malaysia / Asia Times // http://www.atimes. com/atimes/Southeast_Asia/JJ02Ae01.html, 02.10.2008.

9. Sebastian Magnusson The dream of a common language. Popularizing Putonghua in the People's Republic of China / http://lup.lub.lu.se/luur/download?func=downloadFile \& recordOId $=2173016 \&$ fileOId $=2173024$ fall 2011

10. Vitgenshtein L. Logiko-filosofskii traktat http://royallib.ru/read/vitgenshteyn_lyudvig/ logiko_filosofskiy_traktat.html\#163840 